\title{
ERCP: New standards, new challenges
}

\author{
Jonathon Springer MD FRCPC
}

$I^{i}$

$\mathrm{t}$ is time to raise the bar! The article by O'Sullivan et al (pages 154-158) on informed consent and endoscopic retrograde cholangiopancreatography (ERCP) in this issue of the Journal raises important questions and highlights several glaring inadequacies in the way that we inform our patients on the risks and benefits of ERCP. Yet their findings only scratch the surface. The medicolegal implications of ERCP-related complications are not trivial. They accounted for $6 \%$ of the gastrointestinal-related legal actions dealt with by the Canadian Medical Protective Association from 1990 to 1997 . While issues regarding informed consent did not form the basis for most of those cases, they did play a role.

Although the study design (a voluntary survey) and response rate $(40 \%)$ perhaps limit the generalizability of the study, O'Sullivan et al provide insight into the way that many Canadian endoscopists portray ERCP to their patients.

The enormous advances in the past decade in the noninvasive methods of examining the pancreaticobiliary tree (endoscopic ultrasound and magnetic resonance cholangiopancreatography) and our refined appreciation of the complications of ERCP compel us to re-examine the indications for ERCP and the manner in which we involve our patients in the decision-making process.

Informed consent requires the physician to disclose any information that a reasonable person would need to make a decision to accept or reject a treatment or test. 'Adequate' informed consent for ERCP must incorporate information on the indications, complications, benefits and alternatives of the procedure, including disclosure of the material risks (a risk that could alter the patient's decision and is contingent upon the frequency of occurrence and its severity). How many of us do this well, given the current understanding and knowledge of those four spheres as they relate to ERCP? I believe that most of us do not! Evidence-based medicine, and the ethical and legal duty of informed consent force us to change our current practices.

In the present study, a significant proportion of survey respondents, who were generally experienced endoscopists from academic centres, did not routinely mention pancreatitis (9\%), bleeding (12\%) or perforation (27\%) as potential complications of ERCP. Death, although a rare complication $(0.1 \%$ to $0.3 \%)$ of ERCP, is a material risk worthy of inclusion in the consent process - in fact it is mandatory. Yet O'Sullivan et al reveal that $67 \%$ of Ontario respondents never mention that risk, while only $18 \%$ always mention it.

Several prospective, multicentre studies examining the complications of ERCP and sphincterotomy have identified certain patient and procedural-related characteristics that increase the risk of complications $(1,2)$. Sex, normal bilirubin, obscure abdominal pain, difficult cannulation, precut sphincterotomy and procedural numbers may alter a patient's risk of complications in a cumulative manner $(1,2)$. Diagnostic ERCP, particularly in the absence of

St Joseph's Health Center, Toronto, Ontario

Correspondence and reprints: Dr Jonathon Springer, St Joseph's Health Center, 2425 Bloor Street West, Suite 513, Toronto, Ontario M6S 4W4. Telephone 416-766-4587, fax 416-766-5076

Received for publication February 19, 2002. Accepted February 20, 2002 
manometry, still has a limited role, but its place in the investigation of obscure abdominal pain is dubious at best. Should a woman with normal bilirubin and obscure abdominal pain not be informed that the risk of post-ERCP pancreatitis in her situation is extremely high (perhaps up to $40 \%$ ), while the yield is particularly low?

The advent of fellowship training programs, specialized endoscopy centres, and improved availability and accuracy of magnetic resonance cholangiopancreatography and potentially endoscopic ultrasound should begin to restrict the application of ERCP to a largely therapeutic procedure performed by a limited number of well trained experienced endoscopists. There may even come a time when informed consent will entail a personal description of an institution's or individual's technical success and complication rate rather than a representation of the literature. Some authorities already believe that time has arrived (3). These opinions might engender controversy, but our patients do deserve to be 'adequately' informed, do they not?

\section{REFERENCES}

1. Freeman ML, Nelson DB, Sherman S, et al. Complications of endoscopic biliary sphincterotomy. N Engl J Med 1996:335:909-18.

2. Freeman ML, Disario JA, Nelson DB, et al. Risk factors for post-ERCP pancreatitis: a prospective, multicenter study. Gastrointest Endosc 2001:54:425-34.

3. Cotton P. ERCP is most dangerous for people who need it least. Gastrointest Endosc 2001;54:535-6. 


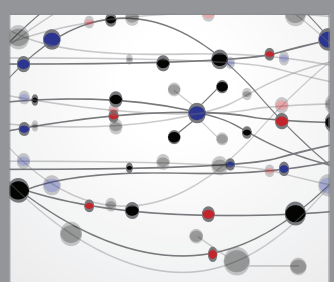

The Scientific World Journal
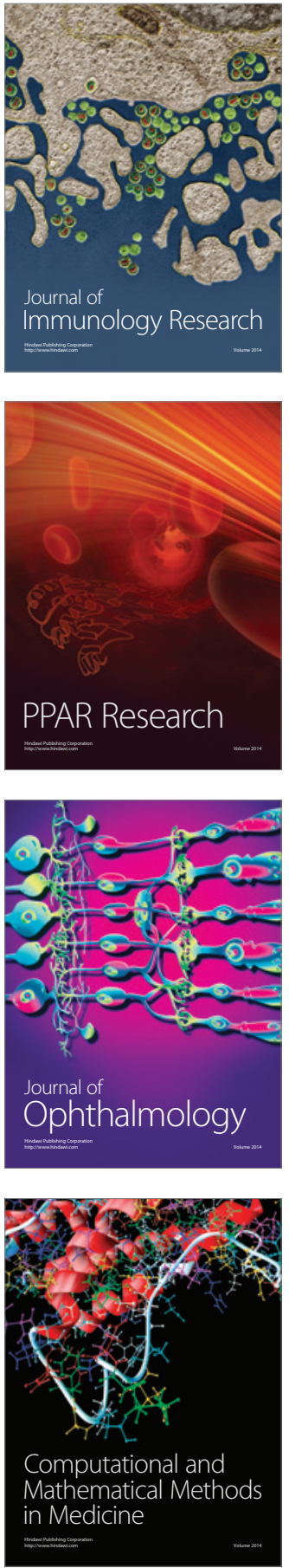

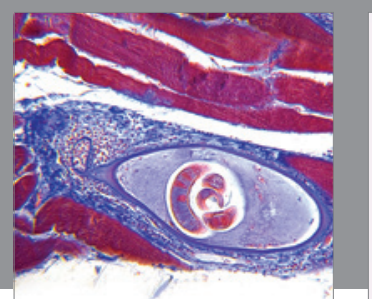

Gastroenterology Research and Practice

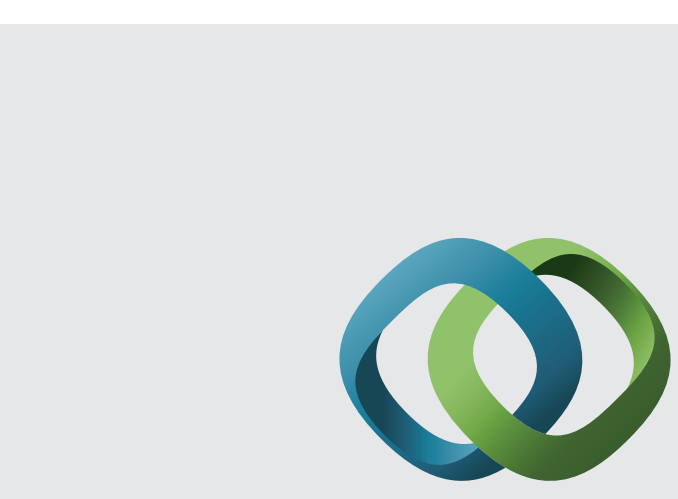

\section{Hindawi}

Submit your manuscripts at

http://www.hindawi.com
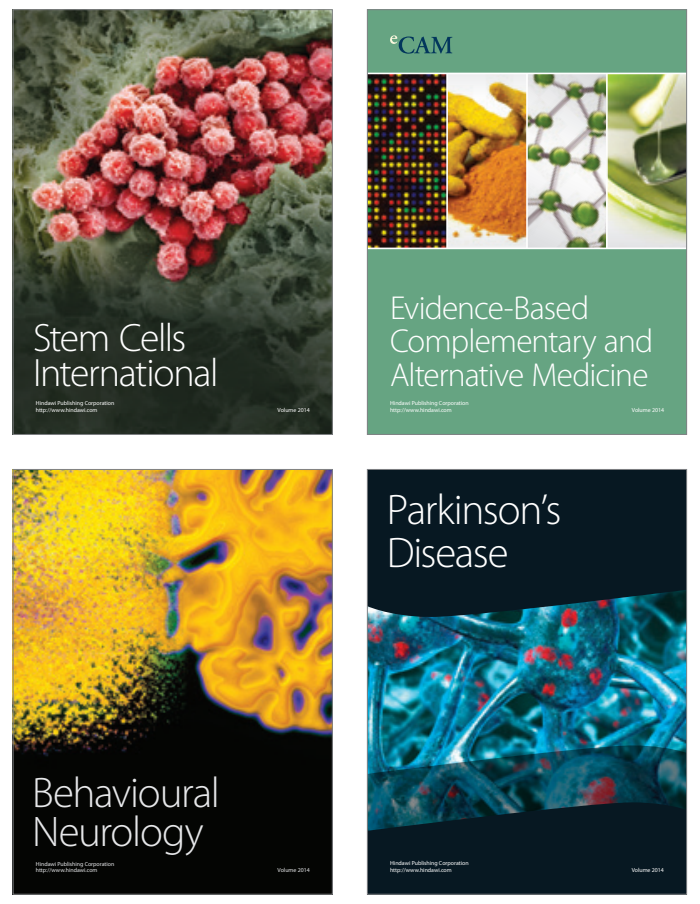
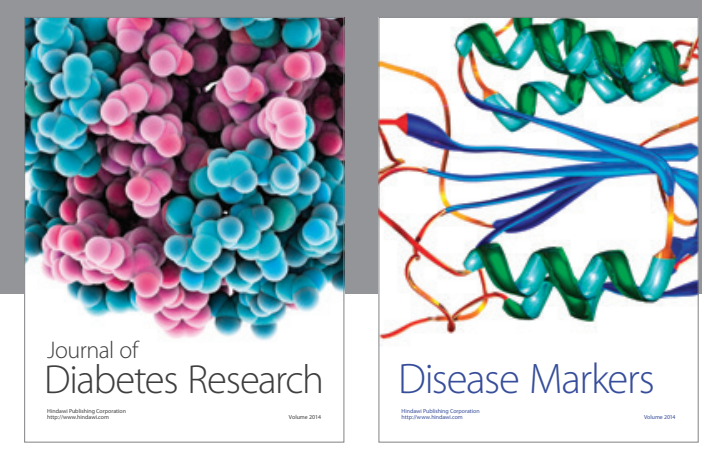

Disease Markers
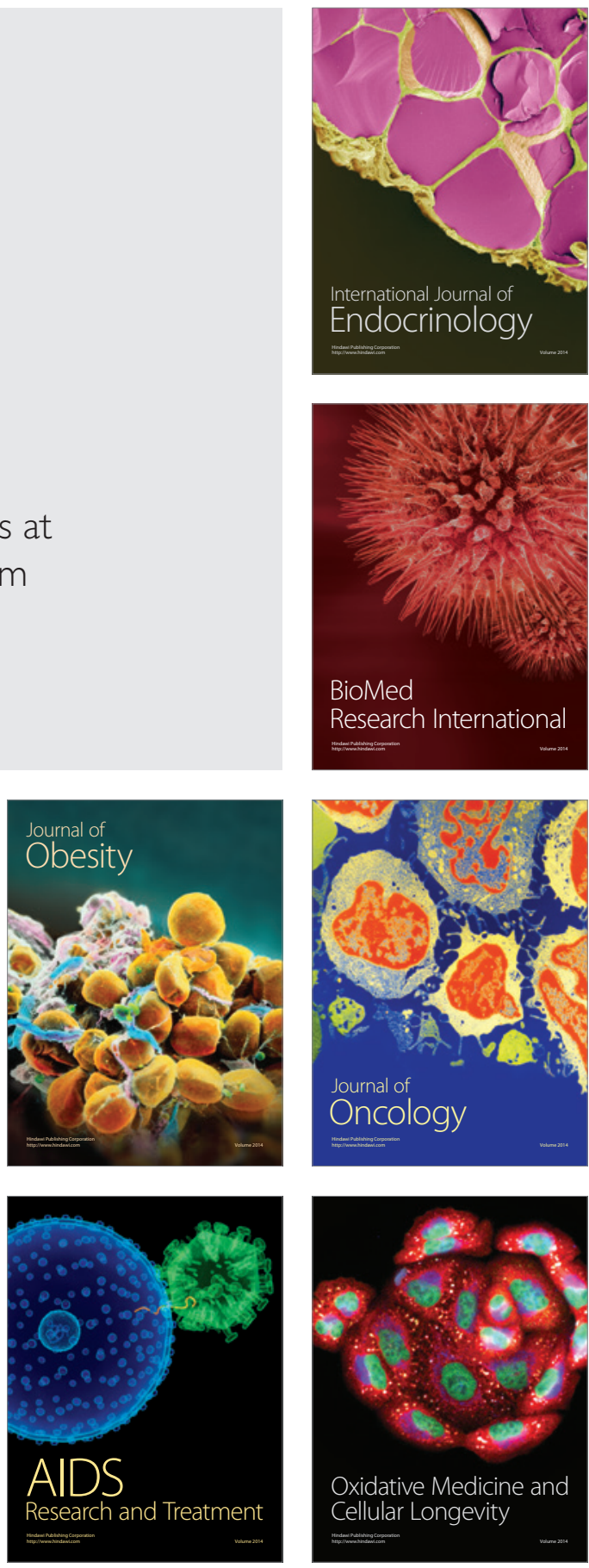